\title{
The environmental impact of municipal waste management systems
}

\author{
Katarzyna Grzesik ${ }^{1, *}$ \\ ${ }^{1}$ AGH University of Science and Technology, Department of Environmental Management and \\ Protection, al Mickiewicza 30, Krakow, Poland
}

\begin{abstract}
An efficient and effective waste management system is one of the key issues for urban areas. Such a waste management system should be effective and economically viable with minimal environmental impact. The Life Cycle Assessment (LCA) methodology is an effective tool for identifying and assessing environmental impacts, it also enables comparing alternative waste management options. The aim of this study is to identify and assess the environmental impacts caused by the waste management system of mixed municipal waste for the city of Krakow for the year 2017. Three scenarios are evaluated for mixed waste: 1) incineration in a new waste-to-energy plant, 2) mechanical-biological treatment (MBT), ballast and stabilized waste is landfilled, refuse derived fuel (RDF) is produced but not incinerated, 3) treatment in the MBT plant, with incineration of RDF in the waste-to-energy plant. The results of modelling show that all scenarios exert a negative impact on the environment in some impact categories, while in other categories - a positive impact. Taking into account the values in all impact categories, the scenario with the lowest overall environmental impact is MBT with incineration.
\end{abstract}

\section{Introduction}

An efficient and effective waste management system is one of the key issues for urban areas, especially in terms of the infrastructure of waste facilities. Municipal waste generation strongly depends on society's affluence, consumption level, and economic development, therefore establishing a sustainable system for waste collection, recycling, recovery and disposal is challenging for modern cities. Such a waste management system should not only be effective and economically viable, but also its environmental impact should be minimal.

The Life Cycle Assessment (LCA) methodology is a valuable tool for identifying and assessing environmental impacts. It is a "cradle to grave" approach, initially developed for assessing the environmental performance of a product's lifespan, but also employed for the evaluation of waste management systems. LCA for municipal waste starts when rubbish is put into the waste bin and ends when the treated (mechanically, biologically or thermally) waste is finally disposed of in a landfill or recycled into a new product. The systemic approach of LCA covers all the impacts associated with waste management, including

* Corresponding author: grzesikk@agh.edu.pl 
collection, transportation, sorting, composting, recycling, incineration, landfilling, as well as obtained useful products (materials, fertilizers, energy). This enables the evaluation of different waste technologies with different patterns of energy consumption or production, and different levels of material recovery. However, performing LCA for waste management is a very complex task and it is usually done with a dedicated model.

The environmental impact of the municipal waste management system in Krakow limited to mixed (residual) waste was evaluated with the EASETECH model employing EDIP2003 methodology. The screening results of the evaluation for three scenarios: incineration, landfilling and the mechanical biological treatment of mixed waste generated in 2010 were announced in a conference paper [1]. In the paper [2] the potential environmental impacts caused by the process of production of refuse-derived fuel (RDF) from mixed municipal waste were identified and assessed. The quantification of the environmental exchanges associated with the mechanical-biological treatment of mixed municipal waste, for a specific MBT plant, based on its annual operation data for the year 2015 was shown in paper [3]. A thorough analysis for two scenarios for the residual waste management of landfilling (year 2010) and incineration (planned for 2016 year) in Krakow was presented in paper [4].

The aim of this study is identify and assess the potential environmental impacts caused by the waste management system for mixed municipal waste for the city of Krakow for the year 2017. Three scenarios are evaluated: 1) mixed waste is incinerated in a new waste to energy plant in Krakow, 2) mixed waste is mechanically-biologically treated (MBT), ballast and stabilized waste after biological processing is landfilled, refuse derived fuel RDF is produced but not incinerated, 3) mixed waste is treated in MBT plant, the produced RDF is incinerated in the waste to energy plant.

\section{Materials and methods}

\subsection{Waste properties and generation}

In the city of Krakow (Poland), which is inhabited by 767348 citizens, $335784.83 \mathrm{Mg}$ of municipal solid waste (MSW) was generated in 2017 [5]; meaning $437.65 \mathrm{~kg}$ per capita. $63.93 \%(214679.47 \mathrm{Mg})$ of MSW was mixed residual waste (not separately collected). A selective collection system has been established in Krakow for recyclables: paper, glass, metal, plastics - the so-called 'dry fraction' (67076.31 Mg); bulky waste $(17017.54 \mathrm{Mg}$ ); biowaste - garden waste $(30482.30 \mathrm{Mg})$; biowaste - food waste $(2729.50 \mathrm{Mg})$; and construction and demolition waste $(3799.71 \mathrm{Mg})$ [5].

The residual waste was analyzed (properties and composition) in the study [6]. The composition of residual waste was defined by 12 main fractions and 34 subfractions and chemical properties were: water content of $41.1 \%$, volatile solids in dry matter $78.3 \%$, heat combustion $13.82 \mathrm{MJ} / \mathrm{kg}$, and lower heating value $7.94 \mathrm{MJ} / \mathrm{kg}$.

\subsection{Scenarios and functional unit}

Three scenarios of mixed waste management are modelled:

1) Incineration scenario: a new thermal treatment plant, with energy recovery (waste-toenergy plant), was opened in Krakow in December 2015 and began full operation in mid 2016. The plant has the capacity of 220 thousand $\mathrm{Mg}$ and it treats mixed (residual) municipal waste as well as post-processing waste from mechanical-biological treatment (MBT). Under this scenario only incineration of mixed waste was modelled. From July 1 to the end of 2016, the plant treated $115582.97 \mathrm{Mg}$ of waste. The residues (post-processing 
waste) after incineration were: fly ash $(2002.02 \mathrm{Mg}$ ); air pollution control (APC) residues (4196.46 Mg); bottom ash (33650.53 Mg); ferrous metal scrap (1022.26 Mg) and nonferrous scrap $(75.96 \mathrm{Mg}$ ). In this period the plant generated $41450.70 \mathrm{MWh}$ of electricity and 362183 GJ of heat, of which $12968.51 \mathrm{MWh}$ of electricity and 5050 GJ of heat were consumed for their own use [7]. Bottom ash, after valorisation and separation of metal scrap, could be used as a substitute for gravel for the bottom layers in road construction. However, fly ash as well as air pollution control (APC) residues require a dedicated treatment. They are disposed by stabilisation and solidification (immobilisation) with Geodur technology, in which iron sulphate and hydraulic binder are the main chemicals used.

2) MBT scenario with no incineration of high calorific fraction: one of the mechanicalbiological treatment plants in Krakow was chosen for modelling, with an annual capacity of 30 thousand $\mathrm{Mg}$. The first step of processing is the initial shredding (tearing of sacs) and separation of recyclables: ferrous metals (magnetically) and non-ferrous metals, glass, paper and cardboard, and plastics (manually). Then waste is screened in a rotary sieve (trommel) into two fractions: over $80 \mathrm{~mm}$ and under $80 \mathrm{~mm}$. Oversize fraction is separated into heavy and light fractions. The heavy fraction (ballast) is sent to a landfill. The light, high calorific fraction (pre-RDF), is shredded and dried. Such prepared refuse derived fuel (RDF) could be incinerated in a cement plant. The incineration in a cement plant is excluded from the modelling. The undersize fraction (mainly bio-waste), undergoes biological treatment - aerobic stabilization (composting), which is done in two steps. First, in bioreactors for 14 days, and then in windrows for 6-10 weeks. After the biological processes, the low quality compost is considered waste (stabilisat) and it is sent to a landfill. Both ballast and stabilisat are landfilled at a modern well equipped facility. Landfill gas is collected and subsequently converted into heat and electricity. Leachate is captured by the drainage system then through sewerage reaches the municipal wastewater treatment plant.

3) MBT scenario with incineration: in this scenario mixed municipal waste is processed in the MBT plant, as described under the second scenario, but the refuse derived fuel (RDF) produced in the MBT plant is sent to be incinerated in the waste-to-energy plant, which is described in the first scenario.

The functional unit for the modelling of scenarios is the total quantity of mixed municipal waste generated in 2017 in Krakow, which is $214679.47 \mathrm{Mg}$. The separate collection, transport and treatment of recyclables, bio-waste, bulky waste, and construction as well as demolition waste is excluded from the modelling, because these elements are the same for all the analysed scenarios.

For the modelling of the collection (from households) and transport of mixed municipal waste to the treatment facilities, data on fuel consumption comes from the study[8]. It is assumed the fuel consumption is the same for all three scenarios, since the incinerator and the MBT plant are located in Krakow, the distances to the city centre are similar. For the transport of final (post - processing) waste to recycling or landfilling facilities, the fuel consumption was calculated based on the actual distances between the incinerator or the MBT plant and recycling plants or the landfill.

\subsection{LCA method for waste management systems}

The modelling of the potential environmental impacts caused by mixed municipal waste scenarios was done with the newest version 2.3.6 of EASETECH software, which is based on the EASEWASTE model [9]. EASETECH enables the modelling the waste management system from the point where waste is collected to the point of final treatment of postprocessing residues. The model calculates emissions to air, water and soil as well as resources consumption. Recycled materials and the energy generated in waste treatment 
plants (e.g. waste-to-energy) are regarded as substitutes for virgin materials or energy produced from fossil fuels, so-called "avoided emissions." The list of exchanges with the environment (emissions and resources consumption) is translated into environmental impacts with Life Cycle Impact Assessment (LCIA) methodologies. ReCiPe was chosen as the method for this modelling as it is commonly used and recommended by European authorities. The ReCiPe method transforms the long list of life cycle inventory results into a limited number of indicator scores. These indicator scores express the relative severity on an environmental impact category. EASETECH calculates the normalised impacts based on the Life Cycle Inventory (LCI) result and the normalisation factors [10]. The ReCiPe method comprises 18 midpoint categories. Four categories: Agricultural Land Occupation, Urban Land Occupation, Natural Land Transformation and Water Depletion were not added to EASETECH because of their strong uncertainty due to geographical variation. Table 1 shows ReCiPe midpoint categories implemented in the EASETECH model. In brackets short names of impact categories are given, which are used in the figures below.

Table 1. ReCiPe midpoint impact categories in the EASETECH model.

\begin{tabular}{|l|l|l|l|}
\hline No & Impact category & No & Impact category \\
\hline 1 & Climate Change (CC) & 8 & Particulate Matter Formation (PMF) \\
\hline 2 & Ozone Depletion (OD) & 9 & Terrestrial Ecotoxicity (TET) \\
\hline 3 & Terrestrial Acidification (TA) & 10 & Freshwater Ecotoxicity (FET) \\
\hline 4 & Freshwater Eutrophication (FE) & 11 & Marine Ecotoxicity (MET) \\
\hline 5 & Marine Eutrophication (ME) & 12 & Ionising Radiation (IR) \\
\hline 6 & Human Toxicity (HT) & 13 & Metal Depletion (MD) \\
\hline 7 & Photochemical Oxidant Formation (POF) & 14 & Fossil Fuel Depletion (FD) \\
\hline
\end{tabular}

\section{Results and discussion}

The EASETECH model calculates the environmental impacts as normalized potential impacts. Normalisation presents a relative value of the environmental impact compared with the impact caused by one average person (normalisation factor), providing a result in person equivalent (PE) unit. A calculated positive value of the normalized impact presents a contribution to the impact on the environment, and a negative value indicates an avoidance of the impact or resource consumption (avoided impact).

\subsection{Results for the incineration scenario}

The results of the modelling the environmental impacts for the incineration scenario is shown in Fig. 1. The significant impact categories for incineration are: ecotoxicity freshwater and marine as well as human toxicity. The values below zero (avoided impact) are observed for fossil fuel depletion, metal depletion and climate change. Avoided impacts result from the saving of fossil fuels through the production of electricity and heat in the waste-to-energy plant, and a lower emission of greenhouse gases as well as the recycling of ferrous and non-ferrous (aluminium) metals separated from bottom ash.

The high values in toxicity categories are due to the treatment of fly ash and APC residues in the ferrox stabilisation process (Geodur), with iron sulphate and cement. In this process heavy metals and other hazardous substances are immobilised and waste is intended for landfilling. However, immobilised substances are modelled as 'stored emissions' with possible leakage in the long-term horizon. 


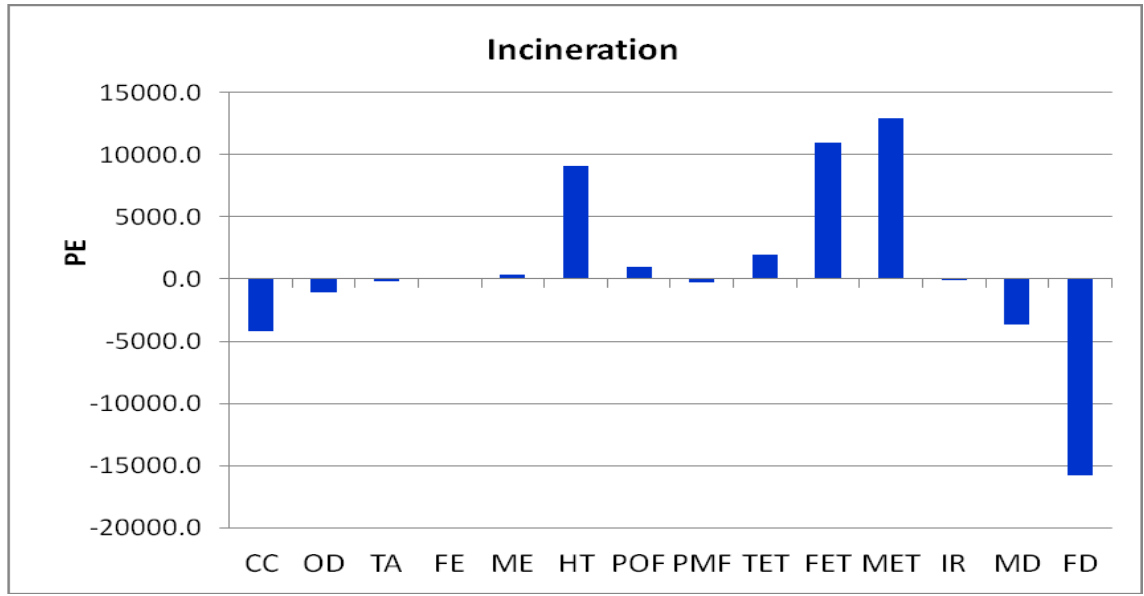

Fig. 1. Normalised environmental impact of the incineration of residual waste.

\subsection{Results for MBT with no incineration scenario}

The results of modelling MBT with no incineration scenario is shown in figure 2.

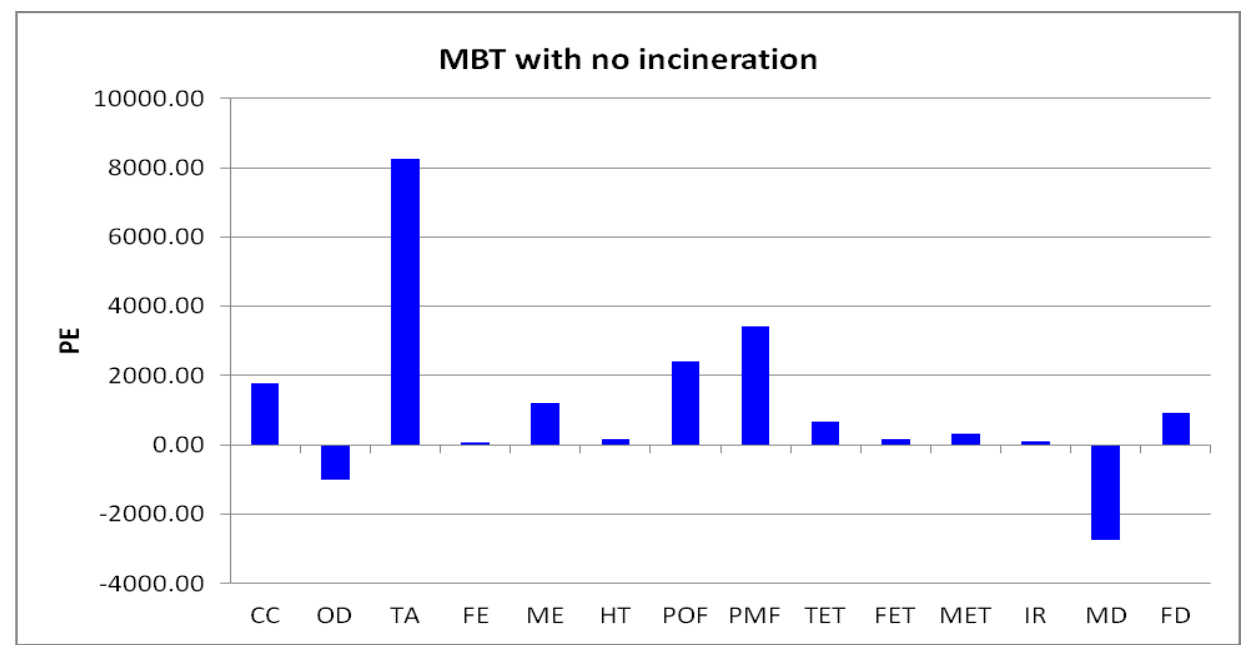

Fig. 2. Normalised environmental impact of mechanical-biological treatment of residual waste with no incineration of the high calorific fraction.

For mechanical-biological treatment of residual waste with no incineration, the highest value is observed in the terrestrial acidification category. Other significant categories: are particulate matter formation, photochemical oxidant formation and climate change with values above zero, as well as metal and ozone depletion with values below zero. To terrestrial acidification and particulate matter formation categories contribute mainly emissions of ammonia from the composting of undersize fraction in reactors, as well as nitrogen oxides from the combustion of fuels in vehicles (transport) and heavy machinery operating in the MBT plant. Composting in the reactors is modelled with $96 \%$ transformation of $\mathrm{N}$ into ammonia. Composting in windrows, which takes longer and is not so intensive as that in reactors, ammonia is oxidised, therefore the emission of this compound is much lower. 
A high value in the category of photochemical oxidant formation is caused by the emission of nitrogen oxides from the combustion of fuels in vehicles and heavy machinery as well as methane emission from the landfilling of stabilisat (low quality compost). The landfilling of stabilisat also contributes to climate change through the emission of methane. The negative values in metal and ozone depletion come from recycling of metals.

\subsection{Results for MBT with incineration scenario}

The results of modelling MBT with incineration scenario is shown in figure 3.

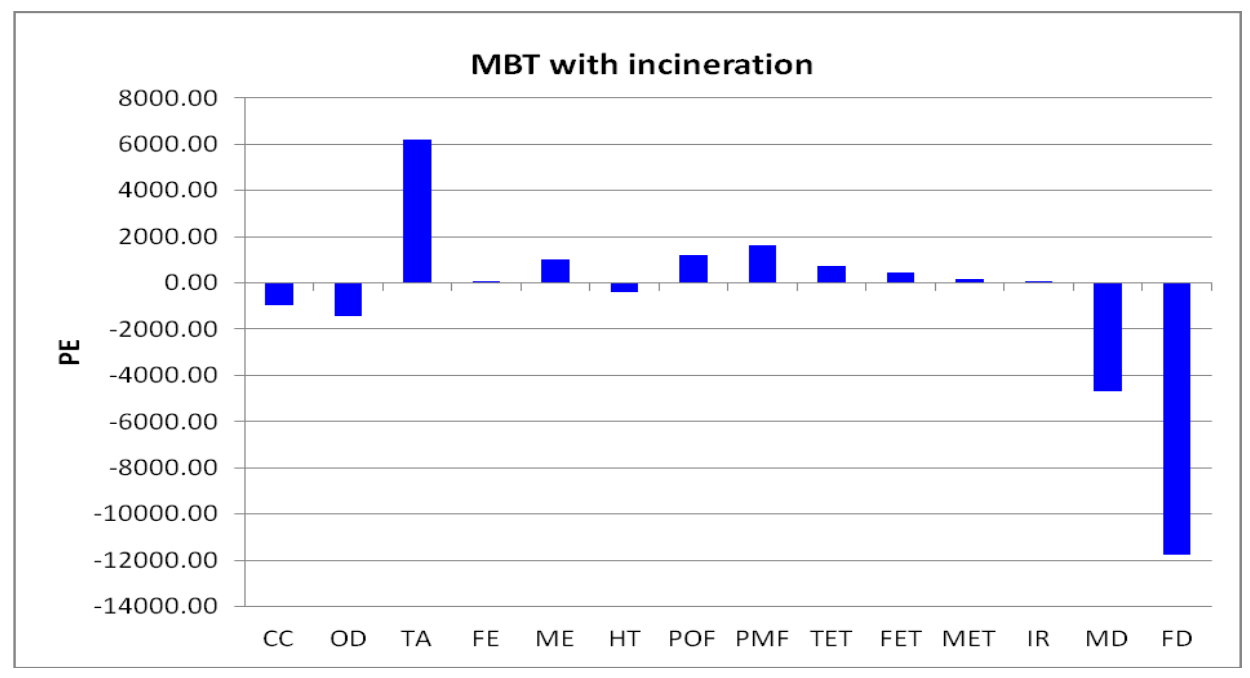

Fig. 3. Normalised environmental impact of mechanical-biological treatment of residual waste with incineration of the high calorific fraction in the waste-to-energy plant.

For the scenario in which residual waste are firstly treated in the MBT plant and then the produced high calorific fraction (RDF) is incinerated in the waste-to-energy plant, the most significant category is fossil fuel depletion with a very high negative value. This is due to the fact that the thermal treatment (waste-to-energy) plant generates electricity (sold to the grid) as well as heat (used by the municipality), therefore fossil fuels are saved as natural resources.

The other significant categories for this scenario are: terrestrial acidification with positive value and metal depletion with a negative value. The high value in the terrestrial acidification category is caused by ammonia emission from the composting process in reactors. The recycling of ferrous metals, which are separated in the MBT plant and additionally after incineration from bottom ash contribute to the metal depletion category.

\subsection{Comparison of scenarios}

The environmental effects of the three scenarios of residual waste treatment, were compared in the EASETECH model using the ReCiPe methodology and assuming the same quantity and quality of waste for all scenarios. The normalized environmental impact results are presented in Fig. 4.

For all scenarios, positive as well as negative values can be observed in different impact categories. The most severe disparity between positive and negative values is observed for the incineration scenario. For this scenario, the negative values in fossil fuel depletion and climate change categories are the highest of all the scenarios. Moreover, the positive values 
in the ecotoxicity impact categories (marine, freshwater and human) are much higher than for the other scenarios; MBT scenarios show negligible values in these impact categories.

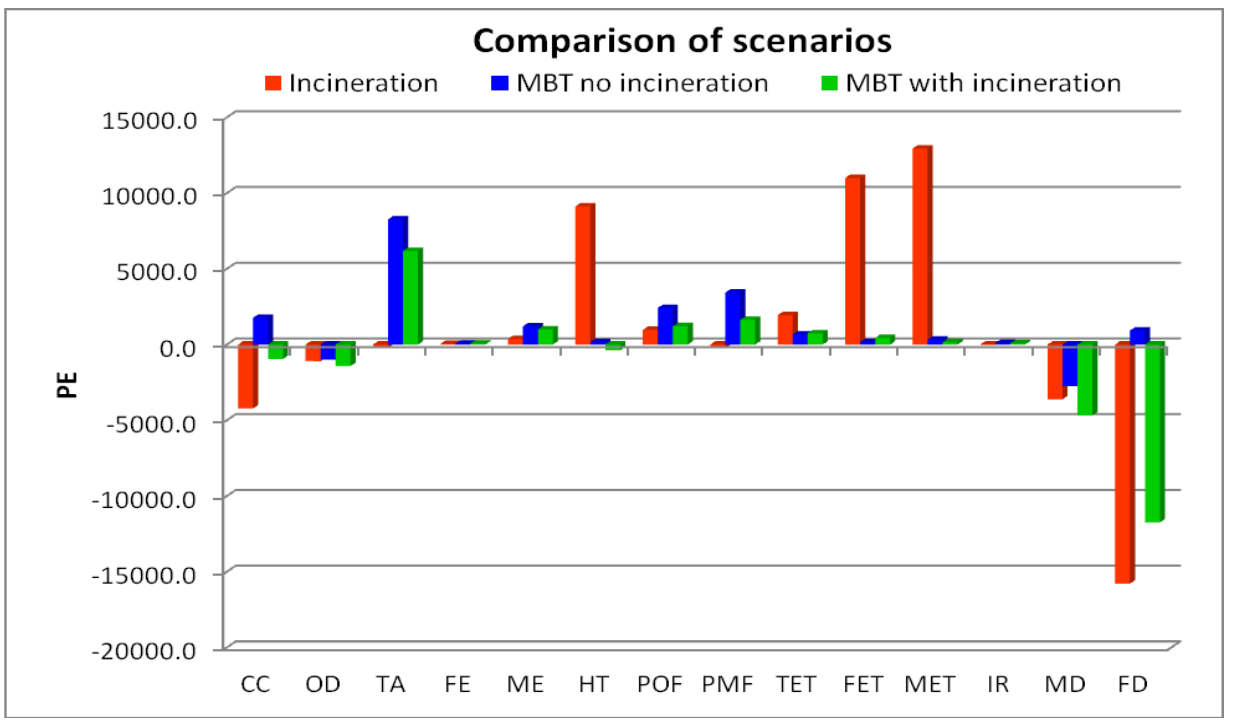

Fig. 4. Normalised environmental impact of three scenarios of residual waste treatment in Krakow.

Two scenarios: incineration and MBT with incineration show negative values in the fossil fuel depletion and climate change categories. In these scenarios fossil fuels are saved, because electricity and district heating are produced from the waste. While the MBT with no incineration scenario shows a positive value, due to the electricity and fuel consumption of heavy machinery for the sorting of waste. Electricity and heat are also generated in MBT with no incineration scenario, from landfilling. Landfill gas is captured and used in CHP (combined heat and power) engines, however, energy produced in this scenario is minimal, due to low methane potential in biologically processed waste fractions.

In two categories: metal depletion and ozone depletion all scenarios show negative values caused by metals recycling. Ferrous and non-ferrous metals are separated from other waste streams in the MBT plant as well as from bottom ash in the waste-to-energy plant.

Only two scenarios: MBT with and without incineration show positive values in terrestrial acidification. This impact category is strongly linked to biological treatment and ammonia emission from the composting process in reactors. Biological treatment also influences two other categories: photochemical oxidant formation and particulate matter formation, values in these categories are highest for the MBT without incineration scenario.

Taking into account the values in all the impact categories, the scenario with the lowest overall environmental impact is MBT with incineration. This scenario generates high quality recyclables, and through their recycling, the virgin materials are saved as natural resources. Moreover, refuse derived fuel (RDF) is produced in the MBT plant, which is transferred for incineration in the waste-to-energy plant. Besides, inert materials (heavy fraction) are separated from waste intended for combustion, therefore the ash content is reduced in RDF. Determinants, which are most significantly affecting the combustion process are: water content, ash content and the heating value. Therefore lowering the water and ash content and increasing the heating value, through the separation processes of mixed waste and producing RDF, improves the environmental performance of the incineration process in the waste-to-energy plant. 


\section{Conclusions}

Life cycle assessment is a valuable tool for comparing different scenarios in terms of environmental performance. Modelling results show that all scenarios exert a negative impact on the environment in some categories, while in other categories the environmental impact is positive. The scenario with the most severe disparity between positive and negative environmental effects is the incineration scenario. Taking into account the values in all impact categories, the scenario with the overall lowest environmental impact is the scenario of MBT with incineration.

This publication and research was funded by grant no 11.11.150.008 for AGH University of Science and Technology, Faculty of Mining Surveying and Environmental Engineering.

\section{References}

1. K. Grzesik, R. Kozakiewicz, B. Bieda, Life cycle assessment for landfilling, incineration and mechanical-biological treatment of residual waste for Krakow city Poland, SGEM2014 Geoconference Vol. 2, Nuclear technologies, recycling, air pollution and climate change, 143-150 (2014)

2. K. Grzesik, M. Malinowski, Life cycle assessment of refuse-derived fuel production from mixed municipal waste, Energy Sources. Part A, Recovery, utilization, and environmental effects, 38, 3150-3157 (2016)

3. K. Grzesik, M. Malinowski, Life Cycle Assessment of Mechanical -Biological Treatment of Mixed Municipal Waste, Environmental Engineering Science, 34, 207 220 (2017)

4. K. Grzesik, Comparative environmental impact assessment of landfilling and incineration of residual waste in Krakow. Environmental Protection Engineering, 43, 135-148 (2017)

5. Urząd Miasta Krakowa. Analiza stanu gospodarki odpadami komunalnymi w gminie miejskiej Krakow za 2017 rok. (2018) Available at: https://www.bip.krakow.pl/?dok id=65239

6. L. Sieja, M. Kalisz, D. Książek, G. Szojda, Badanie ilości i struktury odpadów komunalnych Miasta Krakowa. Raport Końcowy, IETU, Katowice, (2011)

7. M. Wiśniowska, Analysis of the inputs and outputs for the Thermal Waste Treatment Plant in Krakow. Master thesis. AGH University of Science and Technology, Department of Environmental Protection and Management (2017)

8. M. Malinowski, Transport and collection costs analysis of mixed municipal solid waste. Infrastructure and Ecology of Rural Areas, 2, 1179-1191, (2014)

9. J.T. Kirkeby, H. Birgisdottir, T.L. Hansen, T.H. Christensen, G.S. Bhander, M. Hauschild, Evaluation of environmental impacts from municipal solid waste management in the municipality of Aarhus, Denmark (EASEWASTE), Waste Manag Res, 24, 16-26, (2006)

10. J. Clavreul, H. Baumeister, T.H. Christensen, A. Damgaard, An environmental assessment system for environmental technologies. Environ. Model. Softw. 60, 18-30, (2014) 